\title{
Activity Evaluation of CoMo Nanoparticles Supported on Meso-microporous Composites in Dibenzothiophene Hydrodesulphurization
}

\author{
Nastaran Parsafard ${ }^{1, *}$, Mohammad Hasan Peyrovi ${ }^{2}$, Zahra Mohammadian², Niloofar Atashi ${ }^{2}$ \\ ${ }^{1}$ Department of Applied Chemistry, Kosar University of Bojnord, North Khorasan, Iran. \\ ${ }^{2}$ Department of Physical Chemistry, Faculty of Chemistry Science and Petroleum, University of Shahid \\ Beheshti, Tehran, Iran.
}

Received: $3^{\text {rd }}$ August 2019; Revised: 21 $1^{\text {st }}$ October 2019; Accepted: 24 $4^{\text {th }}$ October 2019; Available online: 28th February 2020; Published regularly: April 2020

\begin{abstract}
CoMo-supported mesoporous catalysts were synthesized by 50 wt\% of HZSM-5 and 50 wt\% of FSM-16, KIT-6, and MCM-48. These catalysts were prepared by the wet-impregnation method and pre-sulfided with $\mathrm{CS}_{2}$. The catalytic performance was evaluated for HDS reaction of dibenzothiophene over a temperature range of $250-400{ }^{\circ} \mathrm{C}$ in a micro fixed-bed reactor under atmospheric pressure. The supported CoMo bimetallic catalysts were characterized by XRD, XRF, FT-IR, $\mathrm{N}_{2}$ adsorption-desorption, and SEM. The CoMo/KIT-6/HZSM-5 indicate higher activity than other catalysts at $400{ }^{\circ} \mathrm{C}$ for dibenzothiophene hydrodesulphurization. Also, the best selectivity to cyclohexylbenzene (CHB) is related to CoMo/FSM-16/HZSM-5. The activation energy was also calculated for all prepared catalysts for the conversions of less than 10\%; according to which, the activation energy for CoMo/KIT-6/HZSM-5 is less than other catalysts $(\sim 21 \mathrm{~kJ} / \mathrm{mol})$ which can be related to the appropriate pore size and high surface area of the support. Copyright (C) 2020 BCREC Group. All rights reserved
\end{abstract}

Keywords: Wet-impregnation; Hydrodesulphurization; Dibenzothiophene; KIT-6/HZSM-5

How to Cite: Parsafard, N., Peyrovi, M.H., Mohammadian, Z., Atashi, N. (2020). Activity Evaluation of CoMo Nanoparticles Supported on Meso-microporous Composites in Dibenzothiophene Hydrodesulphurization. Bulletin of Chemical Reaction Engineering \& Catalysis, 15(1), 112-118 (doi:10.9767/bcrec.15.1.5556.112-118)

Permalink/DOI: https://doi.org/10.9767/bcrec.15.1.5556.112-118

\section{Introduction}

Sulphur-containing compounds such as benzothiophene (BT) and dibenzothiophene pollutants which are mainly released from vehicles because of the combustion of the diesel fuels and gasoline [1]. On the authority of environmental regulation, the amount of sulphur in the diesel fuels should be less than $10 \mathrm{ppm}$. Thus, it is necessary to remove the sulphur-content materials or reduce from the exhausts [2]. In order to

* Corresponding Author.

E-mail: n-parsafard@kub.ac.ir (N. Parsafard);

Telp.: +98 58 32257024; Fax: +98 5832427408 reduce the sulphur amount, various methods of desulfurization have been applied, such as: biological desulfurization, adsorption and hydrodesulphurization (HDS). Among these techniques, HDS is the most effective method for removing sulphur on a large scale, which follows catalytic hydrogenation [1]. Consequently, the preparation and development of HDS catalysts with significant activity and selectivity to less dangerous components are crucial in the refining industry [1,3]. Mesoporous supports are the most common materials because of their sufficient pore sizes, pore volumes, and high surface areas. These mesoporous supports, such as: 
SBA-15 [1], MCM-48 [4], and FSM-16 [5], were used as supports in catalytic hydrodesulphurization [6]. The use of mesoporous silicate materials has greatly expanded due to extraordinary properties such as high surface area, adjustable pore size, and rich-pore structure. Although many microporous zeolites, such as: ZSM-5, has been used as supports in HDS reactions [7], the diffusion limitation as a consequence of their low pore sizes in the reactions involving larger substrates, has restricted their application [8]. In the past decades, the use of micro/mesoporous composites has gained considerable attention as catalysts in heterogeneously catalysed reactions. Wu et al. investigated that NiMo/ZSM-5 KIT- 6 catalyst rate for HDS of 4,6-DMDBT is double as $\mathrm{NiMo} / \mathrm{Al}_{2} \mathrm{O}_{3}$ [9]. Wang et al. illustrated that a series of $\mathrm{Ni}$ Mo/ZSM-5-SBA-16 composites, which synthesized by hydrothermal crystallization method, showed high TOF values of 4,6-DMDBT for HDS reaction [10]. Zhang et al. concluded that NiMo/ZSM-5-FDU-12 exhibited better performance than NiMo/FDU-12 [11]. The reason for adding zeolite as a second component of the substrate is not only to increase the specific surface area of the catalysts but also to enhance the access of acidic/basic sites due to the useful role of these properties in catalytic activity [12].

In this study, a series of two partial composites containing HZSM-5 and a second part including a different mesoporous material were prepared. The second part of composites in this research are FSM-16, MCM-48, and KIT-6. It should also be noted that the reason for using different mesoporous in the preparation of composites is to investigate the effect of the nature of each of these materials, the specific surface area and the pore sizes on the performance and activity of the catalysts. Furthermore, the physiochemical properties of composite supports were characterized by different methods and also the performance of catalytic hydrogenation or hydrodesulphurization using dibenzothiophene (DBT) as a model of sulphurcompound was investigated. The effect of the second part of the composition in catalysts was also compared and evaluated.

\section{Materials and methods}

To prepare the catalysts, all materials and chemical reagents with analytical grade were used without further purification. Powder Na/ZSM-5 were purchased from Sigma Aldrich which were ion exchange with the $\mathrm{NH}_{4} \mathrm{NO}_{3} 0.1$ $\mathrm{M}$ solution, for $12 \mathrm{~h}$ at $70^{\circ} \mathrm{C}$ then washed with distilled water in order to use in composites. Ammonium nitrate (99\%), ammonium molybdate $(>99 \%)$, cobalt (II) nitrate hexahydrate $(>98 \%)$, sodium hydroxide $(99.6 \%)$, cetyl trimethyl ammonium bromide ( $>99 \%), \mathrm{HCl}(2 \mathrm{M}, 35$ wt\%), P123, 1-butanol (>99\%) and tetra ethyl ortho silicate $(>99 \%)$ were purchased from Sigma-Aldrich company.

The Mo and Co-promoted catalysts were prepared by the wet impregnation method. With the amount of $10 \mathrm{wt} \%$ molybdenum and 3 wt\% cobalt of $\left(\mathrm{NH}_{4}\right)_{6} \mathrm{Mo}_{7} \mathrm{O}_{24}$ as a source of molybdenum and $\mathrm{Co}\left(\mathrm{NO}_{3}\right)_{2} .6 \mathrm{H}_{2} \mathrm{O}$ as a source of cobalt. In particular, for synthesis of FSM-16 [13], $12 \mathrm{~g}$ silica and $8 \mathrm{~g} \mathrm{NaOH}$ were dissolved in $100 \mathrm{~mL}$ DI water and this mixture was stirred for $3 \mathrm{~h}$ at the room temperature then was dried at $100{ }^{\circ} \mathrm{C}$ for one week. Then it was calcined at $650{ }^{\circ} \mathrm{C}$ for $6 \mathrm{~h}$. In order to obtain kanemite paste $2 \mathrm{~g}$ of the kanemite was dissolved in $25 \mathrm{~mL}$ cetyl trimethyl ammonium bromide and heated for $3 \mathrm{~h}$ at $70{ }^{\circ} \mathrm{C}$. Afterwards, the $\mathrm{pH}$ value was regulated with $\mathrm{HCl}(2$ M) to 8.5 and the mixture was again heated at $70{ }^{\circ} \mathrm{C}$ for $3 \mathrm{~h}$. The left product was filtered and washed with water then dried for $6 \mathrm{~h}$ at $60{ }^{\circ} \mathrm{C}$. In a typical synthesis of KIT-6 [14], $63 \mathrm{~g}$ of $\mathrm{HCl}$ $35 \mathrm{wt} \%$ and $32 \mathrm{~g}$ P123 were dissolved in $115 \mathrm{~g}$ of DI water stirring at $35^{\circ} \mathrm{C}$ for $8 \mathrm{~h}$. After adding $32 \mathrm{~g}$ of 1-butanol, the solution was stirred at $35^{\circ} \mathrm{C}$ for one hour. Afterwards, $68 \mathrm{~g}$ of TEOS was added to the solution and stirred at the same temperature for $24 \mathrm{~h}$. Then the obtained solution was heated up to $130{ }^{\circ} \mathrm{C}$ for $24 \mathrm{~h}$ in an autoclave. The obtained product (KIT-6) was filtered, dried and washed with $\mathrm{HCl}$-methanol and calcinated at $600{ }^{\circ} \mathrm{C}$.

MCM-48 was prepared by the following method [15]. $2.4 \mathrm{~g}$ CTAB was dissolved in $50 \mathrm{~g}$ DI water. Then $50 \mathrm{~mL}$ ethanol and $12 \mathrm{~mL}$ ammonia (32 wt\%) were added to the mixture and then stirred for $10 \mathrm{~min}$. Afterwards $3.4 \mathrm{~g}$ TEOS was added and stirred at room temperature for $2 \mathrm{~h}$. The final products were filtered, washed with water and dried in the air. Finally, the obtained MCM- 48 was calcined for $6 \mathrm{~h}$ at $800^{\circ} \mathrm{C}$.

The mesoporous composite catalysts were prepared by the following method [16]. In order to prepare composites, $0.5 \mathrm{~g}$ of HZSM- 5 were added to the obtained solution during the synthesis of each mesoporous materials. For HZSM-5/KIT-6 after adding TEOS, for HZSM5/FSM-16 after adding kanemite and for HZSM-5/MCM-48 after adding TEOS and preparing the homogeneous solution. The final synthesized composites were dried in an oven at $110^{\circ} \mathrm{C}$ for $24 \mathrm{~h}$ and then calcined at $500{ }^{\circ} \mathrm{C}$ 
for $4 \mathrm{~h}$. These composites summarized as M-Z, $\mathrm{K}-\mathrm{Z}$ and F-Z.

\subsection{Catalyst Characterization}

The physiochemical properties of catalysts were measured by $\mathrm{N}_{2}$ adsorption-desorption isotherms with a micrometrics gas sorption analyzer at $-196{ }^{\circ} \mathrm{C}$. In order to measure pore volumes, specific area, porosity and pore sizes of the supports. To estimate the specific surface area, the Brunauer-Emmett-Teller formula was applied at the relative pressure of $0.99\left(\mathrm{P} / \mathrm{P}_{0}\right)$. To measure the amount of metals, the catalysts were characterized by X-ray Fluorescence (XRF) using a $60 \mathrm{kV}$ XRF Rh. Powder X-ray Diffraction (XRD) was evaluated by X-PERT diffractometer $45 \mathrm{kV}$ and $50 \mathrm{~mA}$ between $2 \theta=$ $1^{\circ}$ and $80^{\circ}$. Fourier Transform infrared (FT-IR) spectra were obtained by a BOMEM spectrophotometer mode Arid-zone TM/BM series in the wave number range of 400 to $4000 \mathrm{~cm}^{-1}$. In order to observe the morphologies of the catalysts field-emission scanning electron microscopy was used by a HITACHI-SU3500 with an accelerating voltage of $30 \mathrm{kV}$.

\subsection{HDS Catalytic Reaction}

The hydrodesulphurization reaction over the prepared catalysts was evaluated in a tempera-

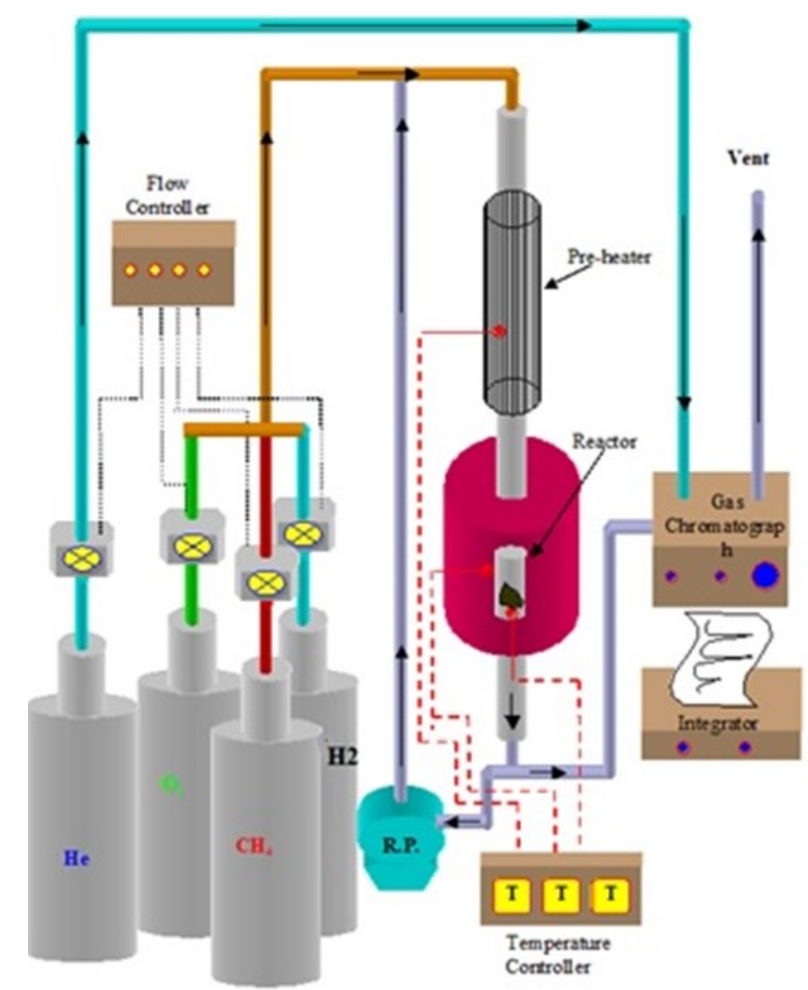

Scheme 1. Schematic diagram of the fixed-bed reactor. ture range of $250-400{ }^{\circ} \mathrm{C}$ using $\mathrm{DBT}$ dissolved in toluene as a model of sulfur-content compound in a continuous Pyrex fixed-bed micro reactor containing $0.5 \mathrm{~g}$ of each catalyst (Scheme 1). The solution of DBT diluted with toluene ( $5 \%$ by volume) was fed into the reactor by a liquid feed pump with LHSV (liquid hour space velocity) of $1 \mathrm{~h}^{-1}$. All catalysts before starting the HDS reaction were pre sulfurized with a solution of $2 \mathrm{wt} \% \mathrm{CS}_{2}$ in cyclohexane and $\mathrm{H}_{2}$ flow of $40 \mathrm{~mL} \cdot \mathrm{min}^{-1}$ at $350{ }^{\circ} \mathrm{C}$ for $2 \mathrm{~h}$ with the rate of $2 \mathrm{~mL} \cdot \mathrm{h}^{-1}$ under atmospheric pressure. After cooling the reactor, the HDS tests were evaluated at a constant atmospheric pressure and $\mathrm{H}_{2}$ flow rate of $40 \mathrm{~mL} \cdot \mathrm{min}^{-1}$ and the DBT solution rate of $2 \mathrm{~mL} \cdot \mathrm{h}^{-1}$. The obtained products were analyzed with an Agilent technology 7890 A GC equipped with a FID detector. The temperature range of the oven in GC was from $80{ }^{\circ} \mathrm{C}$ to $290{ }^{\circ} \mathrm{C}$ with a rate of 10 ${ }^{\circ} \mathrm{C} \cdot \min ^{-1}$.

\section{Results and discussion}

Figure 1 shows the FT-IR spectra of sulfated samples. The presence of peaks at the 1080 $\mathrm{cm}^{-1}$ with shoulder at $717 \mathrm{~cm}^{-1}$, as well as peak at around $1380 \mathrm{~cm}^{-1}$ are related to the symmetric and asymmetric stretching mode of $\mathrm{Si}-\mathrm{O}-\mathrm{Si}$ group, respectively. In addition, the peaks of the hydrogen stretching and bending vibrations of hydrogen in $\mathrm{Si}-\mathrm{OH}$ group appear in the regions of $3463 \mathrm{~cm}^{-1}$ and $1640 \mathrm{~cm}^{-1}$, respectively [17-20]. For ZSM-5 zeolite, the peaks at the 520,810 , and $1000 \mathrm{~cm}^{-1}$ indicates the asymmetric and symmetric stretching vibrations of $\mathrm{T}-$ $\mathrm{O}-\mathrm{T}(\mathrm{T}=\mathrm{Si}, \mathrm{Al})$ bond and vibration of the $\mathrm{T}-\mathrm{O}$ band in $\mathrm{SiO}_{4}$ or $\mathrm{AlO}_{4}$ structure [21]. The peaks related to the terminal $\mathrm{Mo}=\mathrm{O}$ group and the asymmetric stretching vibration of Mo-O-Mo band are seen in regions $900-1050 \mathrm{~cm}^{-1}$ and

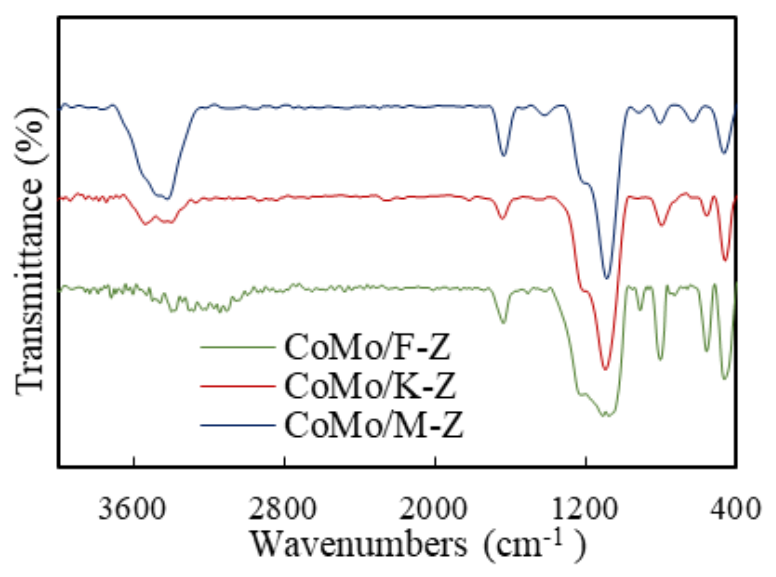

Figure 1. FT-IR spectra of various composites. 
$700-850 \mathrm{~cm}^{-1}$. The vibrations of the tetrahedral and octahedral species of molybdenum appear on the peaks at 830-930, 930-990, and 800-860 $\mathrm{cm}^{-1}$, respectively [3].

Figure 2 demonstrates the X-ray diffraction patterns of sulfated CoMo catalysts. The sharp peak at $2 \theta=2.9^{\circ}$ demonstrates the $d_{211}$ diffraction of the MCM-48 cubic phase. It should be added that the weak peak seen at $2 \theta=3.4^{\circ}$ is related to the $d_{220}$ reflection $[17,20]$. The main characterized peaks of FSM-16 appear at $2 \theta=$ $2.2^{\circ}-2.5^{\circ}, 4.2^{\circ}, 4.7^{\circ}$, and $6.3^{\circ}$, that are attributed to the two-dimensional hexagonal structures (100, 110, 200, and 210) [21]. For KIT-6, highintensity diffraction that seen at $2 \theta=1.09^{\circ}$, indexed to the three-dimensional and regular structure [18]. The diffractions appeared in $2 \theta$ $=6^{\circ}-11^{\circ}$ and $22^{\circ}-25^{\circ}$ show the ZSM-5 phase. The diffractions of metal are not clearly visible, due to the high dispersion and homogeneity of metal particles on composite substrates [3].

The morphology of calcined catalysts is shown in Figure 3 (a-c). In all images, the hexagonal structure of ZSM-5 zeolite is well known. For CoMo/FSM-16-ZSM-5, the nodule-

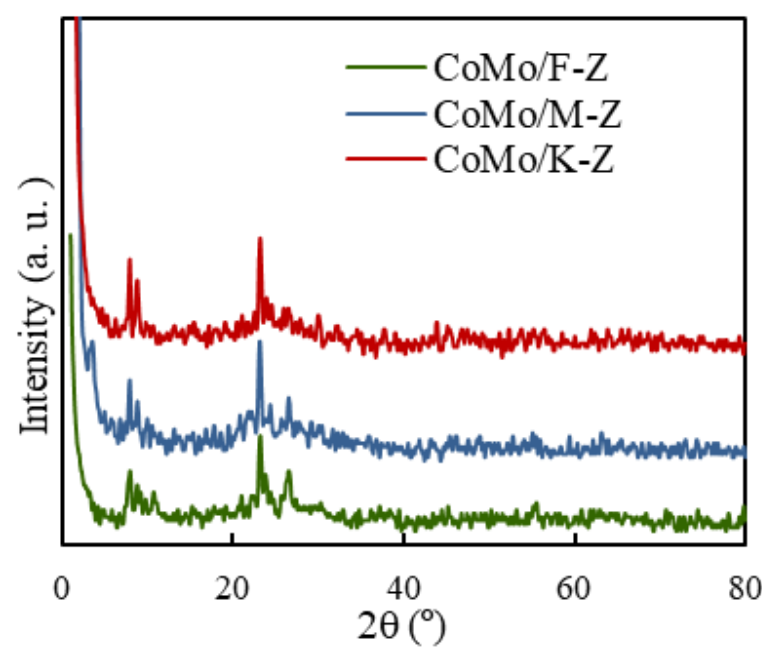

Figure 2. X-ray diffractions of CoMo loaded on mesoporous composites. structure of FSM-16 and the accumulation composition are observed. In addition, the Figure $3(\mathrm{a}, \mathrm{c})$ clearly shows a spherical morphology of MCM-48 and the rock-like of KIT-6. All catalysts have aggregated shape particles after calcination.

The surface properties of catalysts calculated by BET method are presented in Table 1 . Pore diameters indicate that the powders are in the mesoporous classification. As it is obvious, the surface area is in the range of 326-486 $\mathrm{m}^{2} / \mathrm{g}$, and the largest surface area is for CoMo/M-Z catalyst. Also, the pore size of the $\mathrm{CoMo} / \mathrm{K}-\mathrm{Z}$ sample is larger than the others, and it seems that it is convenient to trap the DBT molecule inside the pores and hence hydrogenation. From the SEM images of the prepared catalysts, it can be concluded that all of the constitutional fractions, including microporous zeolite and the mesoporous silica materials, are successfully formed as composites.

To investigate the activity of the catalysts, $0.5 \mathrm{~g}$ of each were subjected to hydrodesulfurization at the temperature of $250-400{ }^{\circ} \mathrm{C}$; specifically, the conversion of the reactants to the products is directly related to variation of the reaction temperature. Table 2 summarizes the results of the activity test at a temperature range of $250-400{ }^{\circ} \mathrm{C}$. According to the data, with increasing reaction temperature, the conversion of dibenzothiophene to products in-

Table 1. Surface and pore properties of CoMo impregnated catalysts.

\begin{tabular}{ccccc}
\hline Catalysts & $\begin{array}{c}S_{\text {BET }} \\
\left(\mathrm{m}^{2} / \mathrm{g}\right)^{\mathrm{a}}\end{array}$ & $\begin{array}{c}d_{\mathrm{p}} \\
(\mathrm{nm})^{\mathrm{c}}\end{array}$ & $\begin{array}{c}V_{\mathrm{p}} \\
\left(\mathrm{cm}^{3} / \mathrm{g}\right)^{\mathrm{b}}\end{array}$ & $\begin{array}{c}S_{\mu} \\
\left(\mathrm{m}^{2} / \mathrm{g}\right)^{\mathrm{a}}\end{array}$ \\
\hline $\mathrm{CoMo} / \mathrm{K}-\mathrm{Z}$ & 408 & 6.70 & 0.83 & 83 \\
$\mathrm{CoMo} / \mathrm{M}-\mathrm{Z}$ & 486 & 2.30 & 0.59 & 127 \\
$\mathrm{CoMo} / \mathrm{F}-\mathrm{Z}$ & 326 & 2.08 & 0.68 & 171 \\
\hline
\end{tabular}

a BET surface area by Brunauer-Emmett-Teller method.

${ }^{\mathrm{b}}$ Average pore volume $\left(\mathrm{V}_{\mathrm{p}}\right)$ and average micropore volume $\left(\mathrm{V}_{\mu}\right)$ by BJH desorption.

${ }^{\mathrm{c}}$ Average pore diameter (4V/A) by BET $\left(\mathrm{d}_{\mathrm{p}}\right)$.
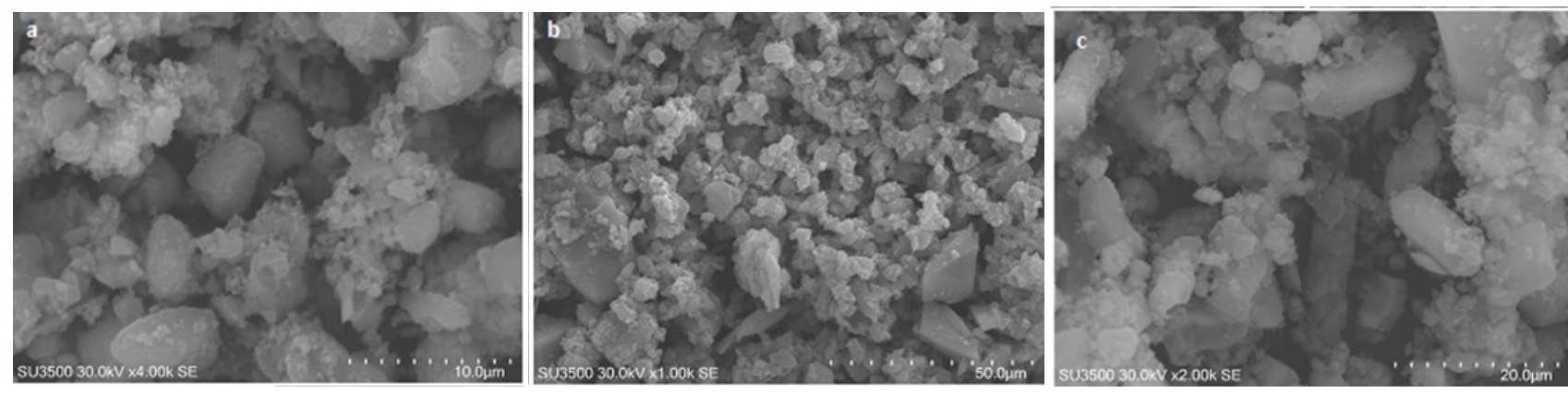

Figure 3. SEM images of CoMo supported on (a) M-Z, (b) F-Z, and (c) K-Z composites. 
creases. It appears that as the reaction temperature increases, the partial pressure of the reactants increases as well. As a result, the adsorption of the reactant and the surface covered by them increase, and the hydrodesulfurization reaction occurs more easily. Also, with increasing reaction temperature, physical adsorption decreases.

Gas chromatography analyses also confirm that the cyclohexyl benzene is the major product. It also seems that by increasing the acidity of the catalysts, the production of cracking products, which are by-products, increases that is not desirable for this reaction.

The results also indicate that the $\mathrm{CoMo} / \mathrm{K}-\mathrm{Z}$ catalyst shows the best performance at all temperatures than other catalysts. It is hypothesized that this may be mainly due to the nature of the supports and their structural features.

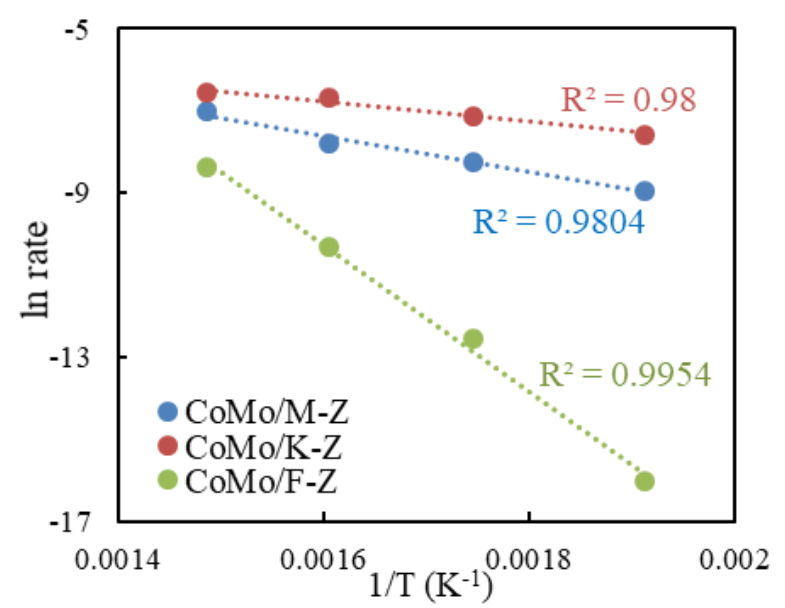

Figure 4. Arrhenius plots of CoMo supported over composites.

Table 2. Activity results of CoMo supported on composites at the temperature range of 250-400 ${ }^{\circ} \mathrm{C}$. ( $T$ : Temperature, $C$ : Conversion, $S$ : Selectivity, and $Y$ : Yield)

\begin{tabular}{ccccc}
\hline Catalysts & $T\left({ }^{\circ} \mathrm{C}\right)$ & $C(\%)$ & $\begin{array}{c}S_{\mathrm{CHB}} \\
(\%)\end{array}$ & $\begin{array}{c}Y_{\mathrm{CHB}} \\
(\%)\end{array}$ \\
\hline & 250 & 45.03 & 78.67 & 35.40 \\
$\mathrm{CoMo} / \mathrm{K}-\mathrm{Z}$ & 300 & 61.95 & 51.82 & 31.61 \\
& 350 & 91.67 & 61.75 & 55.91 \\
& 400 & 98.18 & 64.70 & 62.83 \\
\hline & 250 & 11.32 & 18.41 & 2.02 \\
$\mathrm{CoMo} / \mathrm{M}-\mathrm{Z}$ & 300 & 23.65 & 50.39 & 11.58 \\
& 350 & 29.36 & 88.09 & 25.86 \\
& 400 & 60.75 & 100 & 60.75 \\
\hline & 250 & 0.00 & 27.57 & 0.00 \\
$\mathrm{CoMo} / \mathrm{F}-\mathrm{Z}$ & 300 & 0.77 & 0.16 & 0.01 \\
& 350 & 2.42 & 94.85 & 2.27 \\
& 400 & 15.84 & 100 & 15.84 \\
\hline
\end{tabular}

Also, the obtained data for the selectivity calculations emphasize that the highest selectivity for the $\mathrm{CoMo} / \mathrm{F}-\mathrm{Z}$ catalyst is at $350{ }^{\circ} \mathrm{C}$. It should be noted that although this catalyst had the lowest conversion at all temperatures compared to other catalysts, the highest selectivity was obtained for the production of cyclohexyl benzene using this catalyst. This indicates that the low conversion is also related to the production of cyclohexyl benzene. After calculating the yield as a parameter for an overall review of catalytic activity, it was found that $\mathrm{CoMo} / \mathrm{K}-\mathrm{Z}$ catalyst had the best performance at $400{ }^{\circ} \mathrm{C}(62.83 \%)$. There are two probable mechanisms for HDS reaction depends on the $\mathrm{H}_{2}$ flow rate [22]. At high flow rates of $\mathrm{H}_{2}$, the reaction would prefer the second pathway. With considering the flow rate of hydrogen in this study, the reaction prefers the first mechanism according to more production of cyclohexyl benzene (CHB).

Figure 4 shows the Arrhenius plots for prepared catalysts. The activation energy was calculated for all catalysts under the same conditions and conversions of less than $10 \%$. As it is obvious, the gradient of this plot for the CoMo/F-Z catalyst is much higher than that of other catalysts. This means that much more activation energy is needed to begin the reaction. As a result, this high energy level has caused the catalyst to have the lowest DBT conversion. Conversely, the $\mathrm{CoMo} / \mathrm{K}-\mathrm{Z}$ requires less energy $(21 \mathrm{~kJ} / \mathrm{mol})$ to initiate the hydro desulfurization, which ultimately results in the highest conversion to CHB production. This could be due to the proper pore size and the high surface area, which results in better dispersion of the active phases, thereby enhancing the catalytic performance and specific rate.

$$
R=\frac{f_{D B T} \times d_{D B T} \times C_{D B T}(\%)}{M_{D B T} \times m_{\text {catal }} \times m_{\text {metal }}}
$$

Where $R, f_{\mathrm{DBT}}, d_{\mathrm{DBT}}, M_{\mathrm{DBT}}, m_{\text {catal }}$, and $m_{\text {metal }}$ are rate of reaction (mol/g.s), dibenzothiophene flow $(\mathrm{mL} / \mathrm{s})$, density, molar weight $(\mathrm{g} / \mathrm{mol})$,

Table 3. Specific rate $\left(\times 10^{-3}\right)$ of CoMo supported nanoparticles for DBT hydrodesulphurization.

\begin{tabular}{cccc}
\hline \multirow{2}{*}{$\mathrm{T}\left({ }^{\circ} \mathrm{C}\right)$} & \multicolumn{3}{c}{ Catalyst } \\
\cline { 2 - 4 } & CoMo/K-Z & CoMo/F-Z & CoMo/M-Z \\
\hline 250 & 0.98 & 0.01 & 0.24 \\
300 & 1.48 & 0.03 & 0.56 \\
350 & 2.39 & 0.063 & 0.76 \\
400 & 2.77 & 0.44 & 1.71 \\
\hline
\end{tabular}


mass of catalyst (g), and mass of impregnated metal (wt.\%), respectively.

According to Table 3, investigating the reaction rate changes with temperature and calculating it using Equation (1) indicates that they are in direct relationship with each other in such a way that the increase in temperature increases the relative pressure of the reactants and makes them available for the reaction. As a result, the catalyst rate promotes. The highest rate is obtained for the $\mathrm{CoMo} / \mathrm{K}-\mathrm{Z}$ at $400{ }^{\circ} \mathrm{C}$.

\section{Conclusion}

In this work, a series of cobalt and molybdenum catalysts were prepared. A composite of different mesoporous materials (MCM-48, KIT6 and FSM-16) and ZSM-5 zeolite were used as catalyst supports and their performances were evaluated in the hydro desulfurization reaction of dibenzothiophene in a fixed-bed micro reactor at atmospheric pressure. The results of the activity tests confirm that the increase in reaction temperature significantly increases the conversion of DBT to products. In addition, the results indicate that the best performance for $\mathrm{CoMo} / \mathrm{K}-\mathrm{Z}$ catalyst is achieved at $400{ }^{\circ} \mathrm{C}$ temperature.

\section{Acknowledgment}

We are thankful for this support by the Kosar University of Bojnord (project number 9803231736) and also from Shahid Beheshti University due to its facilities.

\section{References}

[1] Song, S., Yang, X., Wang, B., Zhou, X., Duan, A., Chi, K., Zhao, Z., Xu, C., Chen, Z., Li, J. (2017). Al-modified mesocellular silica foam as a superior catalyst support for dibenzothiophene hydrodesulfurization. Chinese Journal of Catalysis, 38, 1347-1359.

[2] Fujikawa, T., Kimura, H., Kiriyama, K., Hagiwara, K. (2006). Development of ultra-deep HDS catalyst for production of clean diesel fuels. Catalysis Today, 111, 188-193.

[3] Parsafard, N., Peyrovi, M.H., Parsafard, N. (2017). Influence of HZSM-5 content on behavior of CoMo/HZSM5-HMS composite catalysts in hydrodesulphurization of dibenzothiophene. Journal of the Iranian Chemical Society, 14, 1489-1495.

[4] Hussain, M., Song, S.K., Lee, J.H., Ihm, S.K. (2006). Characteristics of CoMo catalysts supported on modified MCM-41 and MCM-48 materials for thiophene hydrodesulfurization. Industrial \& Engineering Chemistry Research, 45, 536-543.
[5] Garg, S., Soni, K., Kumar, M., Bhaskar, T., Gupta, J., Rao, K.R., Dhar, G.M. (2012). Catalytic functionalities of FSM-16 ordered mesoporus silica supported molybdenum hydroprocessing catalysts. Catalysis Today, 198, 263-269.

[6] Nguyen, T.T., Qian, E.W. (2018). Synthesis of mesoporous Ti-inserted SBA-15 and CoMo/TiSBA-15 catalyst for hydrodesulfurization and hydrodearomatization. Microporous and Mesoporous Materials, 265, 1-7.

[7] Agudo, A.L., Benitez, A., Fierro, J.L.G., Palacios, J.M., Neira, J., Cid, R. (1992). Surface properties of molybdenum-impregnated ZSM5 catalysts. Journal of the Chemical Society, Faraday Transactions, 88, 385-390.

[8] Liang, J., Liang, Z., Zou, R., Zhao, Y. (2017). Heterogeneous catalysis in zeolites, mesoporous silica, and metal-organic frameworks. Advanced Materials, 29, 1701139.

[9] Wu, H., Duan, A., Zhao, Z., Li, T., Prins, R., Zhou, X. (2014). Synthesis of NiMo hydrodesulfurization catalyst supported on a composite of nano-sized ZSM-5 zeolite enwrapped with mesoporous KIT-6 material and its high isomerization selectivity. Journal of catalysis, 317, 303-317.

[10] Wang, X., Mei, J., Zhao, Z., Zheng, P., Chen, Z., Gao, D., Fu, J., Fan, J., Duan, A., Xu, C. (2018). Self-assembly of hierarchically porous ZSM-5/SBA-16 with different morphologies and its high isomerization performance for hydrodesulfurization of Dibenzothiophene and 4, 6-Dimethyldibenzothiophene. ACS $\mathrm{Ca}$ talysis, 8, 1891-1902.

[11] Zhang, H., Han, L., Duan, A., Xu, C., Zhao, Z., Wei, Y., Jiang, G., Liu, J., Wang, D., Xia, Z. (2017). Synthesis of micro-mesoporous materials ZSM-5/FDU-12 and the performance of dibenzothiophene hydrodesulfurization. RSC Advances, 7, 28038-28047.

[12] Čejka, J., Mintova, S. (2007). Perspectives of micro/mesoporous composites in catalysis. Catalysis Reviews, 49, 457-509.

[13] Xia, H., Liu, B, Li. Q., Huang, Z., Cheung, A. S.C. (2017). High capacity Mn-Fe-Mo/FSM-16 sorbents in hot coal gas desulfurization and mechanism of elemental sulfur formation. Applied Catalysis B: Environmental, 200, 552-565.

[14] Choi, D.H., Ryoo, R. (2010). Template synthesis of ordered mesoporous organic polymeric materials using hydrophobic silylated KIT-6 mesoporous silica. Journal of Materials Chemistry, 20, 5544-5550.

[15] Kumar, D., Schumacher, K., von Hohenesche, Cd.F., Grün, M., Unger, K. (2001). MCM-41, MCM-48 and related mesoporous adsorbents: 
Their synthesis and characterisation. Colloids and Surfaces A: Physicochemical and Engineering Aspects, 187, 109-116.

[16] Peyrovi, M.H., Parsafard, N., Anajafi, H. (2018). Catalytic performance of micromesoporous materials as the supports for $\mathrm{Pt}$ catalysts in n-heptane isomerization. Chemical Physics Letters, 713, 32-38.

[17] Anbia, M., Kargosha, K., Khoshbooei, S. (2015). Heavy metal ions removal from aqueous media by modified magnetic mesoporous silica MCM-48. Chemical Engineering Research and Design, 93, 779-788.

[18] Soni, K., Rana, B., Sinha, A., Bhaumik, A., Nandi, M., Kumar, M., Dhar, G. (2009). 3-D ordered mesoporous KIT-6 support for effective hydrodesulfurization catalysts. Applied Catalysis B: Environmental, 90, 55-63.

[19] Mohammadian, Z., Peyrovi, M.H., Parsafard, N. (2018). Catalytic performance and kinetics study over novel Ni/activated carbon-FSM-16 catalysts in the BTX mixture for benzene selective hydrogenation. Chemistry Select, 3, 12639-12644.
[20] Peng, R., Wu, C.M., Baltrusaitis, J., Dimitrijevic, N.M., Rajh, T., Koodali, R.T. (2016). Solar hydrogen generation over CdS incorporated in Ti-MCM-48 mesoporous materials under visible light illumination. International Journal of Hydrogen Energy, 41, 4106-4119.

[21] Peyrovi, M.H., Parsafard, N., Mohammadian, Z. (2018). Benzene selective hydrogenation over supported Ni (nano-) particles catalysts: Catalytic and kinetics studies. Chinese Journal of Chemical Engineering, 26, 521-528.

[22] Larabi, C., Nielsen, P.K., Helveg, S., Thieuleux, C., Johansson, F.B., Brorson, M., Quadrelli, E.A. (2012). Bulk hydrodesulfurization catalyst obtained by $\mathrm{Mo}(\mathrm{CO})_{6}$ grafting on the metal-organic framework $\mathrm{Ni}_{2}(2,5$ dihydroxoterephthalate). ACS Catalysis, 2, 695-700. 